\title{
Nop53p is required for late 605 ribosome subunit maturation and nuclear export in yeast
}

\author{
EMMA THOMSON and DAVID TOLLERVEY \\ Wellcome Trust Centre for Cell Biology, University of Edinburgh, Edinburgh EH9 3JR, Scotland
}

\begin{abstract}
We report that Ypl146cp/Nop53p is associated with pre-60S ribosomal complexes and localized to the nucleolus and nucleoplasm. In cells depleted of Nop53p synthesis of the rRNA components of the $60 \mathrm{~S}$ ribosomal subunit is severely inhibited, with strikingly strong accumulation of the $7 \mathrm{~S}$ pre-rRNA and a $5^{\prime}$ extended form of the $25 \mathrm{~S}$ rRNA. In cells depleted of Nop53p pre-60S subunits accumulate in the nucleus. However, a heterokaryon assay demonstrated that Nop53p is not transferred between nuclei, indicating that it is not released into the cytoplasm. We conclude that Nop53p is a late-acting factor in the nuclear maturation of $60 \mathrm{~S}$ ribosomal subunits, which is required for normal acquisition of export competence. The strong accumulation of preribosomes in the Nop53p-depleted strain further suggests that it may participate in targeting aberrant preribosomes to surveillance and degradation pathways.
\end{abstract}

Keywords: nucleolus; ribosome synthesis; Saccharomyces cerevisiae; RNA surveillance

\section{INTRODUCTION}

The 805 yeast ribosome is composed of a large $60 \mathrm{~S}$ subunit, containing the 25S, 5.8S, and 5S rRNA, and a small $40 \mathrm{~S}$ subunit containing only the $18 \mathrm{~S}$ rRNA species. The $18 \mathrm{~S}$, $5.8 \mathrm{~S}$, and $25 \mathrm{~S}$ rRNA species are co-transcribed as a $35 \mathrm{~S}$ polycistronic precursor in the nucleolus. The $35 \mathrm{~S}$ prerRNA undergoes a series of endonucleolytic cleavages and exonucleolytic processing steps to yield the mature species (see Fig. 1). This process has been extensively studied in the genetically tractable model organism Saccharomyces cerevisiae, and most intermediate steps are well characterized.

Processing of the pre-rRNAs occurs within preribosomal particles that contain, in addition to pre-rRNA and ribosomal proteins, a plethora of transacting processing, modification and assembly factors, most of which are essential for cell viability. These nonribosomal proteins form transient interactions with the preribosomal particles, generating dynamic structures with continuously changing protein compositions. Affinity purification techniques (Rigaut et al. 1999) have allowed the composition of several $90 \mathrm{~S}$, pre-40S, and pre-60S complexes to be elucidated. The

Reprint requests to: David Tollervey, Wellcome Trust Centre for Cell Biology, University of Edinburgh, Kings Buildings, Edinburgh EH9 3JR, Scotland; e-mail: d.tollervey@ed.ac.uk; fax: 44-131 6507040.

Article and publication are at http://www.rnajournal.org/cgi/doi/ 10.1261/rna.2720205. earliest complex identified corresponds to a 90S particle, containing the $35 \mathrm{~S}$ rRNA precursor in addition to factors implicated in 40S synthesis (Dragon et al. 2002; Grandi et al. 2002). Pre-rRNA cleavage at site $A_{2}$, within the $90 \mathrm{~S}$ particle, gives rise to pre-60S and pre- $40 \mathrm{~S}$ particles. The pre-40S subunit is believed to then rapidly leave the nucleolus and traverse the nucleoplasm and nuclear pore complexes to the cytoplasm, where maturation is completed (Schafer et al. 2003). In contrast, the 60S subunit undergoes extensive rearrangement and processing within the nucleolus and nucleoplasm prior to its export to the cytoplasm. $60 \mathrm{~S}$ maturation therefore takes longer than $40 \mathrm{~S}$ synthesis, and more intermediate particles have been identified (Baßler et al. 2001; Harnpicharnchai et al. 2001; Saveanu et al. 2001; Fatica et al. 2002; Nissan et al. 2002; Saveanu et al. 2003). In both pathways, early particles are nucleolar, intermediate stage particles are nucleolar and nucleoplasmic, while late processing complexes are nucleoplasmic/cytoplasmic (for review, see Tschochner and Hurt 2003). The transit of the maturing preribosomes through the nucleolus, nucleoplasm, and cytoplasm, may provide an important means to spatially and temporally separate the steps in ribosome assembly and processing, and to ensure that they take place in the prescribed order.

Ypl146c/Nop53p was identified as a factor copurifying with components of the nuclear pore complex (Rout et al. 2000), as were many other late-acting ribosome synthesis factors. Nop53p was subsequently purified as a component 


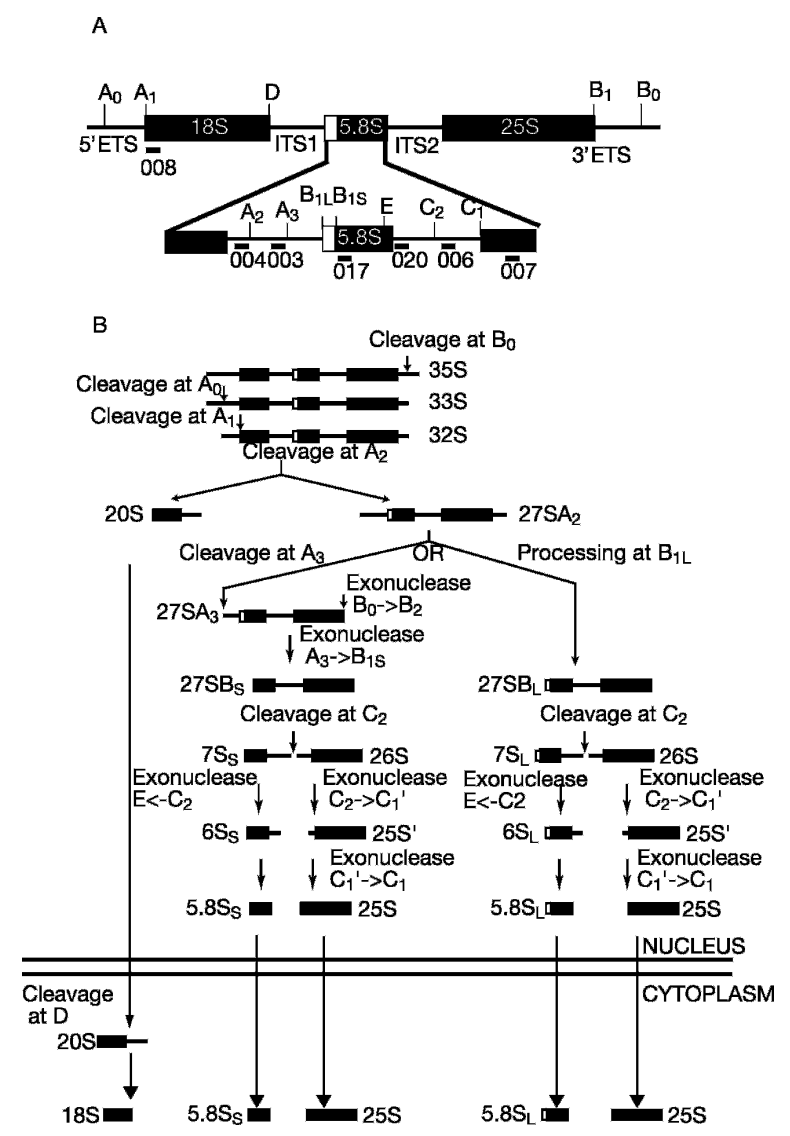

FIGURE 1. The pre-rRNA processing pathway in Saccharomyces cerevisiae. (A) The structure of the 35S rRNA precursor and locations of processing sites. The pre-rRNA encodes the $18 \mathrm{~S}, 5.8 \mathrm{~S}$, and $25 \mathrm{~S}$ rRNAs, which are flanked by the $5^{\prime}$ and $3^{\prime}$ external transcribed spacers ( $5^{\prime}$ ETS and $3^{\prime}$ ETS) and separated by internal transcribed spacers 1 and 2 (ITS1 and ITS2). (B) The pre-rRNA processing pathway. The 35S precursor is generated by co-transcriptional cleavage at site $B_{0}$ within the $3^{\prime}$ ETS. This is followed by endonucleolytic cleavages at sites $A_{0}$ within the $5^{\prime} \mathrm{ETS}, \mathrm{A}_{1}$ at the $5^{\prime}$ end of the mature $18 \mathrm{~S}$ rRNA and $\mathrm{A}_{2}$ within ITS1. Cleavage at $\mathrm{A}_{2}$ separates the precursors to the $40 \mathrm{~S}$ and $60 \mathrm{~S}$ subunits and generates the $20 \mathrm{~S}$ and $27 \mathrm{SA}_{2}$ pre-rRNAs. $20 \mathrm{~S}$ is subsequently exported from the nucleus to the cytoplasm where maturation to $18 \mathrm{~S}$ is completed. The $27 \mathrm{SA}_{2}$ pre-rRNA follows one of two alternate pathways: around $85 \%$ is cleaved at the $\mathrm{A}_{3}$ site within ITS2, followed by $5^{\prime}-3^{\prime}$ exonucleolytic processing generating the $27 \mathrm{SB}_{\mathrm{s}}$ pre-rRNA. The remaining $15 \%$ is processed at site $B_{1 L}$, which is located $8 \mathrm{nt} 5^{\prime}$ to $\mathrm{B}_{1 \mathrm{~S}}$, yielding the $27 \mathrm{SB}_{\mathrm{L}}$ pre-rRNA. These two alternate forms of 27SB are cleaved within ITS2 at site $\mathrm{C}_{2}$, yielding $26 \mathrm{~S}$ pre-rRNA and the long and short forms of $7 \mathrm{~S}$. The 7S pre-rRNAs are converted to mature $5.8 \mathrm{~S}_{\mathrm{L}}$ and $5.8 \mathrm{~S}_{\mathrm{S}}$ by a multistep $3^{\prime}$ exonuclease pathway. Maturation of $26 \mathrm{~S}$ to $25 \mathrm{~S}$ rRNA similarly proceeds by a twostep $5^{\prime}$ exonuclease pathway.

of a number of late pre-60S particles, including those defined by Ciclp, Nug1p, Ipi2p, Sdalp, Arxlp, and Nog1p (Baßler et al. 2001; Saveanu et al. 2001; Nissan et al. 2002). The early Ciclp-associated complex is localized to the nucleolar compartment, the Nuglp complex is enriched in both the nucleolus and the nucleoplasm, while the later complexes defined by Ipi2 and Sda1 are confined to the nucleoplasm. The most mature complex containing Nop53p, the Arx1p-associated particle, localizes to the nucleoplasm and cytoplasm. In addition, Nop53p was found to associate with Trf4p (Ho et al. 2002), a protein that was recently implicated in pre-rRNA surveillance (LaCava et al. 2005; Wyers et al. 2005).

Here we describe the role of Ypl146cp/Nop53p in the processing of rRNA precursors and nuclear export of pre605 ribosomal subunits.

\section{RESULTS}

Nop53p is a conserved protein of $52.55 \mathrm{kDa}$, the human homolog of which encodes GLTSCR2, a predicted glioma tumor suppressor (Smith et al. 2000). The protein has an unusual composition: Nop53p has 43\% charged (DEHKR) residues (database average is $25 \%$ ) and $39 \%$ hydrophobic (ACFGHILMTVWY) (database average is 57\%). The protein is predicted to be largely $\alpha$-helical, with a strong predicted coiled-coil domain between residues 326 and 360. It is likely to form homo- or heterodimers of the leucine-zipper type, since it has three leucine residues in this region with perfect heptad separation (M. Dlakic, pers. comm.). It seems quite unlikely that Nop53p has an enzymatic function, but it may form protein-protein interactions that are important for the structures of the preribosomes.

\section{Nop53p associates with pre-60S particles}

Affinity purification of preribosomal particles suggested that Nop53p might be a component of pre-60S particles. To confirm its association with preribosomal particles we used a C-terminal fusion between NOP53 and a TAP tag at the genomic locus (Ghaemmaghami et al. 2003), expression of which remained under the control of the endogenous promoter. Growth of the tagged strain was indistinguishable from the wild type (data not shown), indicating that the fusion protein is functional. Co-sedimentation of Nop53TAP with preribosomal particles was tested by fractionation of a cell lysate on a $10 \%-50 \%$ sucrose gradient. Western blot analysis of gradient fractions (Fig. 2A) showed that Nop53TAP sediments in two broad peaks. Northern hybridization (Fig. 2B,C) reveals that the lower peak of Nop53-TAP cosediments with $27 \mathrm{~S}$ pre-rRNA species (Fig. $2 \mathrm{~B}$ ), consistent with its association with pre-60S particles. The slower sedimenting Nop53-TAP fraction may correspond to the free protein plus smaller complexes of ribosome synthesis factors. Similar sized nonribosomal complexes have been reported for several other ribosome synthesis factors (Fatica et al. 2002; Dez et al. 2004; Horsey et al. 2004).

We also attempted to use Nop53-TAP to purify associated preribosomes, but were unable to detect any coprecipitation of RNAs, suggesting that the tag is not accessible. 


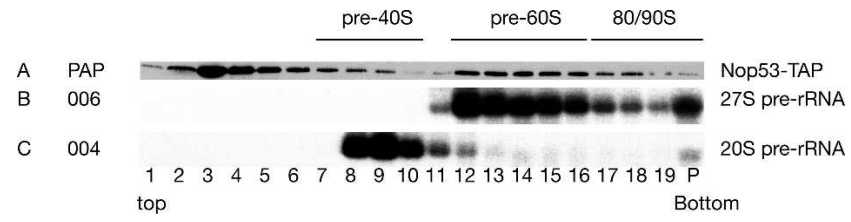

FIGURE 2. Nop53p co-sediments with pre-60S ribosomes. Cell lysate from a strain expressing Nop53-TAP was loaded on to a $10 \%$ to $50 \%$ sucrose gradient. (A) Western blotting using a peroxidase conjugated IgG (PAP) that recognizes Nop53-TAP. (B) Northern hybridization with a probe against the $27 \mathrm{SA} / 27 \mathrm{SB}$ pre-rRNA components of pre-60S ribosomes. $(C)$ Northern hybridization with a probe against the $20 \mathrm{~S}$ pre-rRNA component of pre-40S ribosomes. The positions of sedimentation of pre-40S, 60S, and $90 \mathrm{~S}$ particles are indicated. Fraction numbers are indicated, where 1 is the top gradient fraction and $\mathrm{P}$ is the pellet.

\section{Nop53p is required for pre-rRNA processing}

The YPL146c/NOP53 ORF was initially reported to be essential in systematic deletion analyses (Winzeler et al. 1999). To characterize the role of Nop53p in ribosome synthesis we therefore constructed an $\mathrm{N}$-terminal $3 \mathrm{HA}$ nop53 fusion, under the control of the glucose repressible GAL1 promoter, by one-step PCR (Longtine et al. 1998). Growth curves, RNA extractions, and Northern analyses were performed for two independently isolated GAL::3HA-nop53 strains. Data are presented only for one strain, but very similar results were obtained from analyses of the second isolate (data not shown). On galactose containing complete medium the growth rates of the GAL::3HA-nop53 strain and otherwise isogenic wild type were identical (data not shown). Following transfer to repressive, glucose medium, the growth rates of both strains were initially identical (Fig. 3A). However, growth of the GAL::3HA-nop53 strain slowed progressively, commencing $3 \mathrm{~h}$ after transfer to glucose. Residual growth was observed for the GAL::3HA-nop53 strain (12-h doubling time) even $24 \mathrm{~h}$ after transfer to glucose medium (data not shown). Western blot analysis (Fig. 3B) shows that the abundance of 3HA-Nop53p is strongly reduced after only $1 \mathrm{~h}$ on glucose media. It is possible that the $\mathrm{N}$-terminal 3HA tag may destabilize the protein leading to its rapid turnover. Growth of the GAL::3HA-nop53 strain was retarded on semipermissive, YPGRS medium ( $1 \%$ yeast extract, $2 \%$ bacto-peptone, $2 \%$ galactose, $2 \%$ raffinose, $2 \%$ sucrose) that reduces the level of expression. The apparently normal growth of the GAL::3HA-nop53 strain on galactose may therefore be due to the overexpression that is often seen for GAL-regulated constructs during growth on galactose.

Ribosome synthesis in the Nop53p-depleted strain was assessed by pulse-chase labeling with $\left[8{ }^{3} \mathrm{H}\right]$ adenine $1 \mathrm{~h}$ after glucose addition (Fig. 4). In the Nop53p-depleted strain, adenine incorporation into pre-rRNA was reduced approximately fourfold (estimated from the relative exposures required to give approximately equal signals for the wildtype and Nop53p-depleted samples). Analysis of the high molecular weight RNAs (Fig. 4A) revealed that maturation of the $35 \mathrm{~S}$ primary transcript and $32 \mathrm{~S}$ pre-rRNA was mildly delayed, as shown by their persistence in later time points in the depleted strain and increased abundance relative to the $27 \mathrm{~S}$ and $20 \mathrm{~S}$ pre-rRNA compared to the wild type. Consistent with this, the appearance of the 27SA, 27SB, and 20S pre-rRNA also showed some delay. The most striking phenotype was the almost complete loss of synthesis of the mature 25S rRNA, whereas $18 \mathrm{~S}$ synthesis continued. Analysis of low molecular weight RNAs (Fig. 4B) showed that the synthesis of the mature $5.8 \mathrm{~S}$ rRNA was also greatly inhibited, whereas the $5 \mathrm{~S}$ rRNA, which is independently transcribed, was much less affected. Notably, accumulation of the 7S pre-rRNA was similar in the Nop53p-depleted and wild-type cells. Relative to the wild type, the level of the $7 \mathrm{~S}$ pre-rRNA is substantially higher than that of the 27SB pre-rRNA, its immediate precursors (see Fig. 1B). An experiment with longer pulse and chase times (Fig. 4C) showed that the accumulated 7S species persists over a long period, with very low levels of mature $5.8 \mathrm{~S}$ synthesized.

Steady-state levels of mature rRNAs and pre-rRNAs were also analyzed by Northern hybridization and primer extension during depletion of 3HA-Nop53p. Total RNA was extracted during growth on galactose medium (0-h time points in Fig. 5) and at time points following transfer to

A

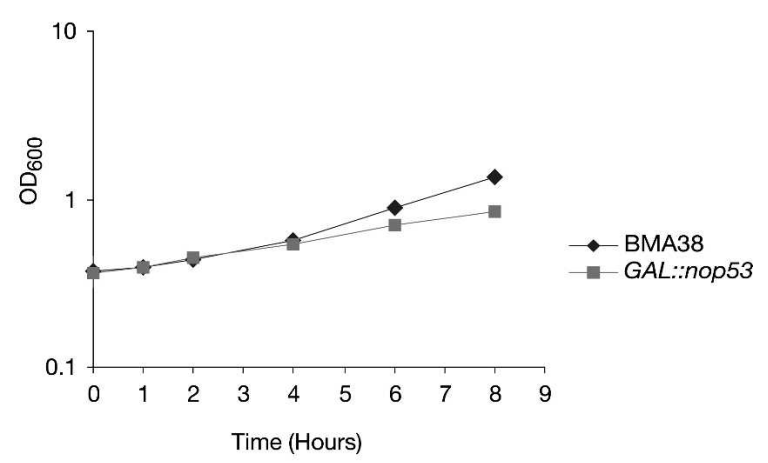

B

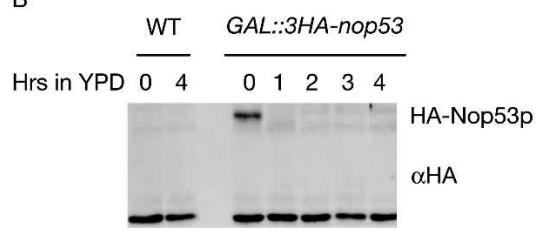

FIGURE 3. Depletion of 3HA-Nop53p rapidly inhibits cell growth. (A) Growth rate of wild-type (diamonds) and GAL::3HA-nop53 (squares) strains following a transfer from permissive galactose medium to nonpermissive glucose medium for the times indicated. Cells were maintained in exponential growth throughout the time course by addition of prewarmed medium. (B) Western analysis of 3HANop53p depletion. 3HA-Nop53p was decorated with rabbit anti-HA primary antibody, which was subsequently detected using antirabbit IgG linked to horseradish peroxidase. 
A

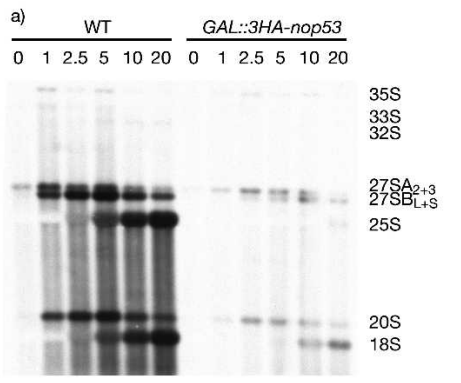

b)

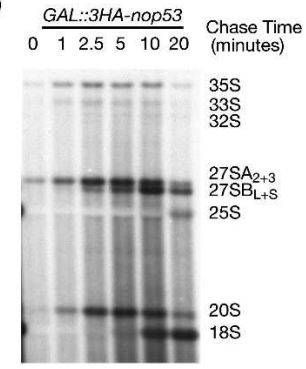

( $3 \times$ exposure)

B

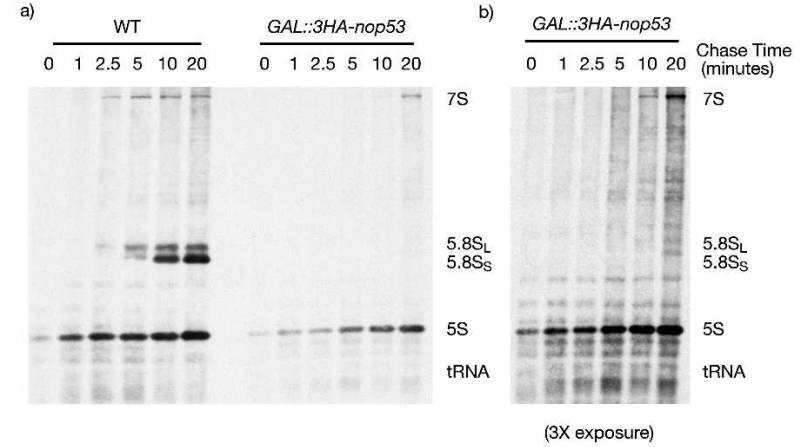

C

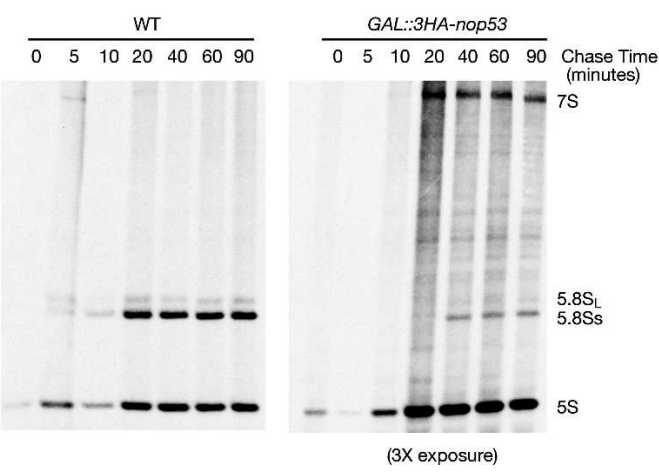

FIGURE 4. Depletion of Nop53p inhibits pre-rRNA processing. Wild-type and GAL::3HA-nop53 strains were transferred to glucose containing medium for $1 \mathrm{~h}$ and then pulse labeled with $\left[8-{ }^{3} \mathrm{H}\right]$ adenine for $2 \min (A, B)$ or $5 \mathrm{~min}(C)$, followed by a chase with a large excess of cold adenine for the times indicated. (A) High molecular weight RNA was glyoxyl denatured and resolved on a $1.2 \%$ agarose gel. $(B, C)$ Low molecular weight RNA was separated on $6 \%$ polyacrylamide/8.3 M Urea gels. In $A$ and $B$, panel $a$ shows the same exposure for the wild-type and GAL::3HA-nop53 samples, while panel $b$ shows a threefold longer exposure of the GAL::3HA-nop53 samples. In $C$, the exposure shown for the GAL::3HA-nop53 samples is threefold longer than for the WT.

glucose medium. Consistent with the pulse-chase data, depletion of Nop53p led to modest accumulation of the $35 \mathrm{~S}$ and $32 \mathrm{~S}$ pre-rRNAs (Fig. 5Aa). This was combined with the appearance of a low level of the aberrant $23 \mathrm{~S}$ species (Fig. $5 \mathrm{Ad}$ ), which is generated when cleavage at site $A_{3}$ precedes cleavage at sites $A_{0}, A_{1}$, and $A_{2}$ (see Fig. 1B). These early cleavage steps are essential for the formation of the $20 \mathrm{~S}$ pre-rRNA and the mature $18 \mathrm{~S}$ rRNA component of the 40S ribosome. There was, however, little alteration in the levels of $20 \mathrm{~S}$ pre-rRNA or $18 \mathrm{~S}$ rRNA (Figs. 5Ad and e). A delay in these early cleavage steps is a common phenotype when factors required for $60 \mathrm{~S}$ synthesis are depleted, probably due to indirect effects (for review, see Venema and Tollervey 1999). Mild increases were seen in the levels of the $27 \mathrm{SA}_{2}$ and $27 \mathrm{SB}$ pre-rRNAs (Fig. 5Aa,b), but the 7S pre-rRNA was much more dramatically accumulated (Fig. 5Ba). PhosphorImager quantification $4 \mathrm{~h}$ after transfer to glucose medium, showed that the $7 \mathrm{~S}$ pre-rRNA is 12 -fold more abundant in the Nop53p depleted strain than in the wild type (data not shown).

Three forms of $3^{\prime}$ extended 5.8S rRNA precursors exist in wild-type cells. The $7 \mathrm{~S}$ pre-rRNA is extended to the $\mathrm{C}_{2}$ cleavage site within ITS2, while the $5.8 \mathrm{~S}+30$ and $6 \mathrm{~S}$ pre-$$
\text { A }
$$

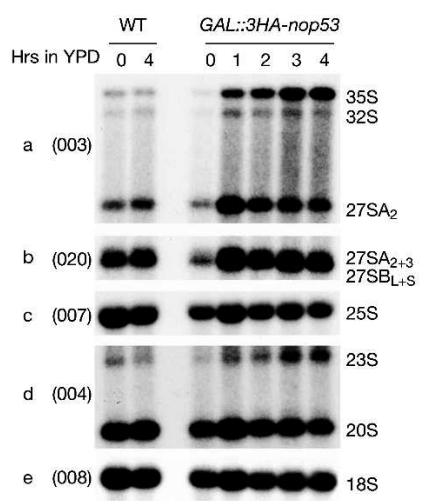

c
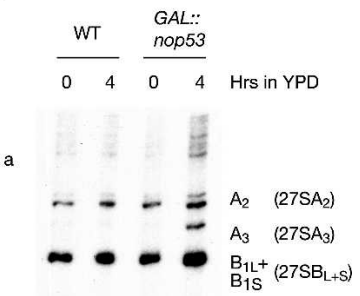

B

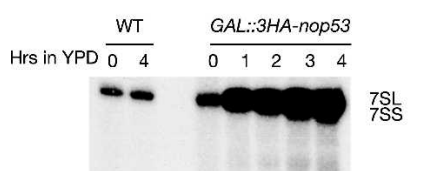

a (020)
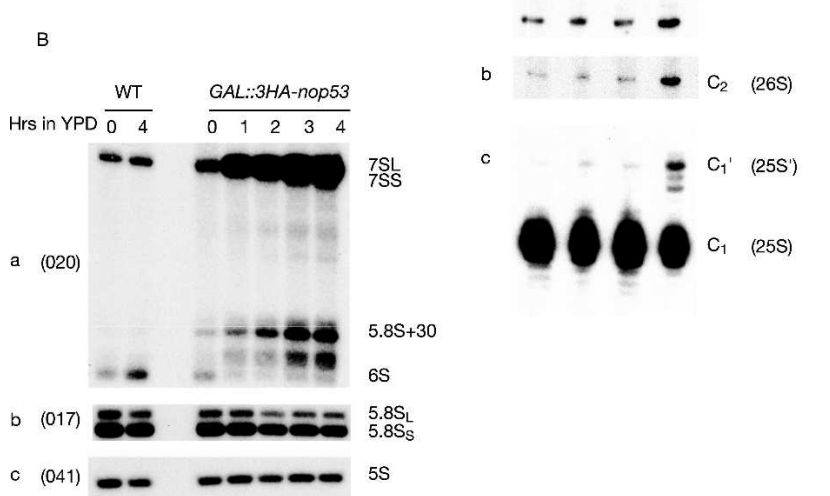

FIGURE 5. Nop53p is required for rRNA processing. Total RNA was extracted during growth on galactose medium ( 0 -h time points) and at intervals following transfer to glucose media. The same RNA preparations were used in each analysis. (A) Northern analyses of high molecular weight RNA species resolved on a $1.2 \%$ agarose gel following glyoxyl denaturation. $(B)$ Northern analyses of low molecular weight RNA species resolved on a $6 \%$ polyacrylamide/ $8.3 \mathrm{M}$ urea gel; $4 \mu \mathrm{g}$ of total RNA was used in Northern analyses and the hybridization probes are indicated on the left in parentheses. $(C)$ Primer extension analysis utilizing an oligonucleotide that hybridized within the mature $25 \mathrm{~S}$ rRNA, $40 \mathrm{nt}$ from the $5^{\prime}$ end (oligo 007). Pre-rRNA processing sites are indicated, with the corresponding pre-rRNA species indicated in parentheses. Each panel is taken from the same gel, but with different exposure times: (a) $16 \mathrm{~h},(b) 40 \mathrm{~h}$, and (c) $6 \mathrm{~h}$. 
rRNAs represent intermediates in the $3^{\prime}$ maturation of $7 S$ to mature 5.8S rRNA. The increase in 7S levels was combined with a modest accumulation of the $5.8 \mathrm{~S}+30$ pre-rRNA and the disappearance of the $6 \mathrm{~S}$ precursor (Fig. $5 \mathrm{Ba}$ ). This pattern indicates that $3^{\prime}$ processing of the $7 \mathrm{~S}$ pre-rRNA by the exosome complex is inhibited, as is subsequent processing of $5.8 \mathrm{~S}+30$, which specifically requires the Rrp6p component of the nuclear exosome (Briggs et al. 1998; Allmang et al. 1999). Short and long forms are detected for the mature $5.8 \mathrm{~S}$ rRNA and its precursors, due to $5^{\prime}$ end heterogeneity that results from the use of alternative processing pathways in ITS1 (see Fig. 1B). The ratios of long to short forms were unaltered during depletion of Nop53p (Fig. 5Bb). Little alteration was seen in the levels of the mature rRNAs during the time course analyzed, but these RNAs are stable and are depleted only slowly by growth.

Primer extension analyses (Fig. 5C) were performed using oligo 007, which hybridizes within the $25 \mathrm{~S}$ region of the pre-rRNA (see Fig. 1A). Consistent with the Northern hybridization data, mild increases in the primerextension stops at sites $A_{2}$ and $B_{1}$ were seen in the Nop53pdepleted strain (Fig. 5Ca), reflecting accumulation of the $27 \mathrm{SA}_{2}$ and $27 \mathrm{SB}$ pre-rRNAs. The $27 \mathrm{SA}_{3}$ pre-rRNA, which cannot be readily detected in Northern analyses, was accumulated in the Nop53p-depleted strain, as shown by the stop site at $\mathrm{A}_{3}$ (Fig. 5Ca). Its level was, however, significantly lower than those of the $27 \mathrm{SA}_{2}$ or $27 \mathrm{SB}$ pre-rRNAs, indicating that the delay in its maturation is modest. PrerRNA cleavage at site $C_{2}$ generates both the $7 \mathrm{~S}$ and the $26 \mathrm{~S}$ pre-rRNA species (Fig. 1B). A moderate accumulation of $26 \mathrm{~S}$ pre-rRNA was seen following depletion of Nop53p, together with the accumulation of a shorter $5^{\prime}$ extended $25 \mathrm{~S}\left(25 \mathrm{~S}^{\prime}\right)$ species identified by the $\mathrm{C}_{1}{ }^{\prime}$ stop. These observations show the inhibition of $5^{\prime}-3^{\prime}$ exonuclease processing during the final stages of $25 \mathrm{~S}$ maturation. In Figure $5 \mathrm{C}$ the exposure shown for the $\mathrm{C}_{2}$ stop (Fig. 5Cb) is 6.5-fold longer than for $\mathrm{C}_{1}{ }^{\prime}$ (Fig. 5Cc), indicating that the amount of accumulated $25 \mathrm{~S}^{\prime}$ pre-rRNA was substantially greater than $26 \mathrm{~S}$.

The $25 S^{\prime}$ pre-rRNA, which is $5^{\prime}$ extended by $\sim 6$ nucleotides relative to the mature $25 \mathrm{~S}$ rRNA, was previously shown to be associated with late, nucleoplasmic pre-60S complexes (Gadal et al. 2002; Saveanu et al. 2003). It seems likely that the accumulated 7S seen in Nop53p-depleted strains is associated with late pre-ribosomes that also contain the $25 S^{\prime}$ pre-rRNA.

\section{Nop53p is a nuclear protein required for the export of the large subunit}

To determine the localization of Nop53p, a construct expressing a C-terminal GFP fusion protein was integrated at the endogenous locus using a PCR strategy (Longtine et al. 1998). The nucleolus was identified in fixed cells by indirect immunofluorescence using a mouse anti-Noplp antibody
(Wu et al. 1998) and a goat antimouse alexafluor-555 conjugated secondary antibody. The nucleoplasm was visualized with DAPI. Nop53-GFP localized to both the nucleolus and the nucleoplasm (Fig. 6A). Additionally a halo of GFP appeared around the DAPI and Nop1p signals, possibly corresponding to the nuclear envelope and/or nuclear pore complexes. It was previously reported that Nop53p interacts with components of the nuclear pore complex (Rout et al. 2000). The pattern of Nop53-GFP localization would be consistent with association with late pre-60S particles.

To ascertain whether Nop53p accompanies pre-60S particles from the nucleus through the NPC to the cytoplasm a heterokaryon assay was performed. A strain expressing Nop53-GFP was crossed with a kar1-1 strain, in which mating and cell conjugation is not followed by

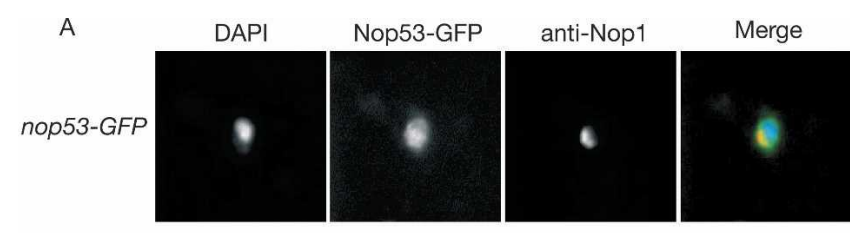

B

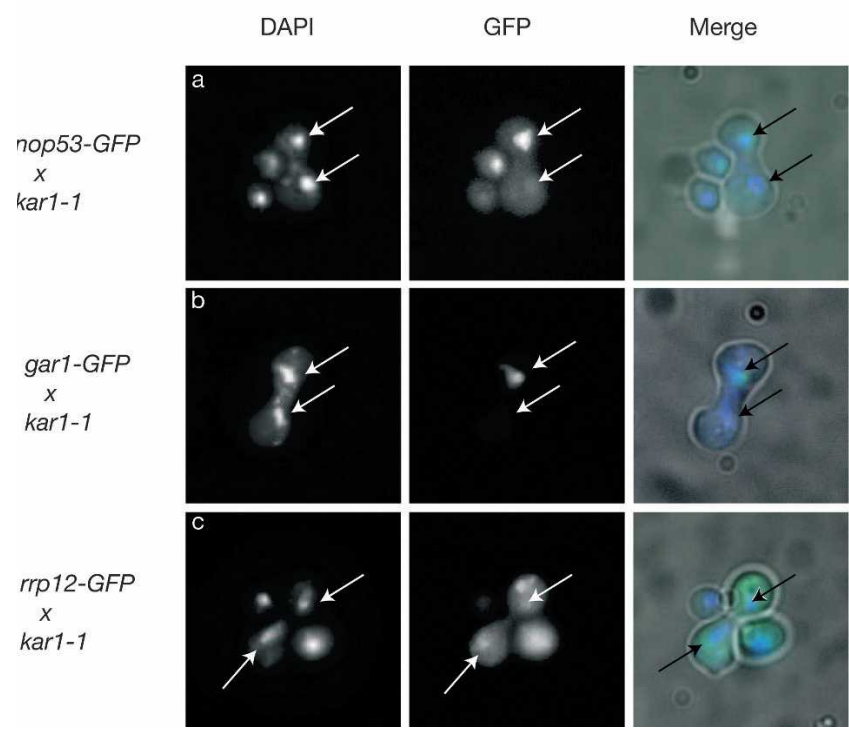

FIGURE 6. Nop53p is restricted to the nucleolus and nucleoplasm. (A) Nop53-GFP localizes to both the nucleolus and nucleoplasm. The nucleolus was visualized using an anti-Noplp antibody (Wu et al. 1998), which was subsequently recognized by an Alexafluor conjugated secondary antibody. The nucleoplasm was visualized by DAPI staining. (B) Nop53p does not shuttle from the nucleus to the cytoplasm. Strains expressing Nop53-GFP, Gar1-GFP, and Rrp12-GFP were grown in YPD media, mated with a karl-1 mutant strain, and incubated at $25^{\circ} \mathrm{C}$ until heterokaryons formed. Localization of the GFP-tagged proteins in heterokaryotic cells is shown for (a) Nop53GFP, (b) Gar1-GFP, and (c) Rrp12-GFP. Cells are shown with DAPI stained nucleoplasm. GFP and DAPI signals are also shown merged with DIC bright field images. Arrows indicate the positions of nuclei in the heterokaryons. 
nuclear fusion, leading to heterokaryon formation (Vallen et al. 1992). Nop53-GFP was localized to only one of the nuclei in the heterokaryons (Fig. 6Ba), indicating that the protein does not actively shuttle between the nucleus and the cytoplasm. The characterized nuclear-cytoplasmic shuttling protein Rrp12-GFP was found in both nuclei of the heterokaryon (Fig. 6Bc), while the nonshuttling nucleolar protein Gar1-GFP was present in only one of the nuclei in heterokaryons (Fig. 6Bb; Oeffinger et al. 2004). We conclude that Nop53p dissociates from pre-60S particles prior to or during the process of export to the cytoplasm.

To determine whether Nop53p is required for nuclear export of the large ribosomal subunit, the localization of the $60 S$ reporter construct Rpll1b-eGFP (Stage-Zimmermann et al. 2000) was analyzed in wild-type and GAL::3HAnop53 strains. Under permissive conditions Rpl11b-eGFP was found throughout the cell in both wild-type and mutant cells (Fig. 7Aa,c). Following a shift to nonpermissive glucose media for $2 \mathrm{~h}$, nuclear accumulation of the Rpl11b-eGFP signal was visible in the GAL::3HA-nop53 strain (Fig. 7Ad), and by $4 \mathrm{~h}$ the accumulation was substantial (Fig. 7Ae).

As shown in Figure 7B, nuclear accumulation of Rpl11pGFP was observed in both the nucleoplasm (shown by the DAPI-stained region) and in the nucleolus (decorated by antibodies against the nucleolar marker Nop1p). No accumulation of $40 \mathrm{~S}$ particles was seen in the GAL::3HAnop53 strain as judged by the localization of Rps2p-eGFP (data not shown) (Milkereit et al. 2003).

\section{DISCUSSION}

The data presented here establish that Ypl146cp/Nop53p is a late-acting nuclear component of the $60 \mathrm{~S}$ ribosome synthesis machinery. Sucrose gradient analyses showed the co-sedimentation of Nop53-TAP with the $27 \mathrm{~S}$ pre-rRNA component of the pre-60S particles. Depletion of Nop53p under the control of a repressible GAL promoter severely inhibited the synthesis of the $25 \mathrm{~S}$ and $5.8 \mathrm{~S}$ rRNA components of the mature $60 \mathrm{~S}$ subunits. In the absence of Nop53p pre-60S particles accumulate in the nucleus, as judged by the nuclear retention of the Rpl11b-eGFP reporter. These pre-60S particles are likely to also contain the $7 \mathrm{~S}$ and $25 \mathrm{~S}^{\prime}$ pre-rRNAs, which were strongly accumulated in Nop53p-depleted strains. This indicates that the presence of Nop53p is required for pre-60S particles to attain export competence. Depletion or mutation of several different proteins inhibits both $60 \mathrm{~S}$ subunit export and processing of $7 \mathrm{~S}$ pre-rRNA to 5.8S (Gadal et al. 2001a, 2002; Nissan et al. 2002; Galani et al. 2004; Oeffinger et al. 2004), although no previously characterized mutation resulted in the very high levels of $7 \mathrm{~S}$ accumulation observed following depletion of Nop53p. Maturation of $7 \mathrm{~S}$ pre-rRNA to $5.8 \mathrm{~S}$ rRNA is reported to occur in the nucleoplasm (Nissan et al. 2002), indicating that it may be directly linked to the acquisition of export

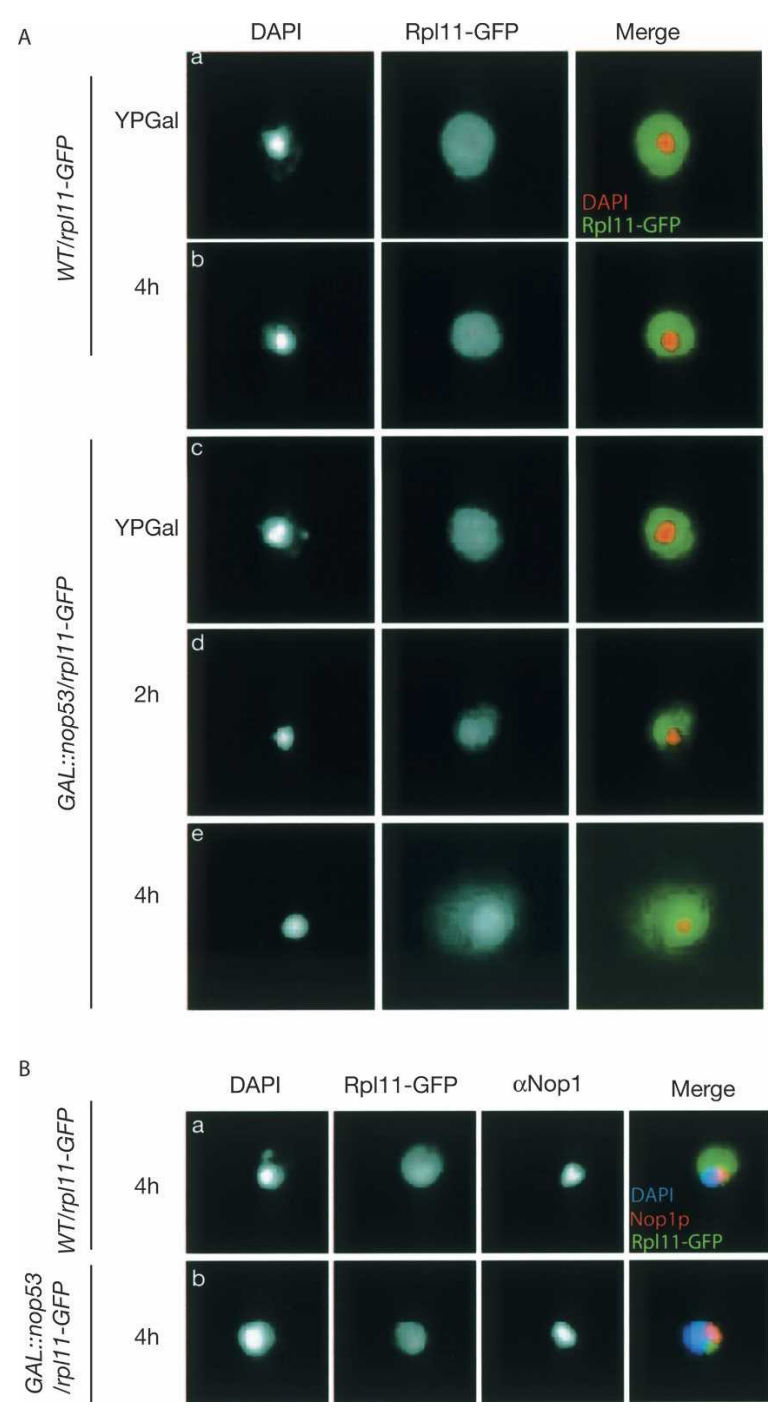

FIGURE 7. Nop53p is required for the nuclear-cytoplasmic export of the 60 S subunit. (A) Wild-type and GAL::3HA-nop53 strains were transformed with a centromeric plasmid expressing Rpll1b-eGFP (shown in green). Cells were pregrown in galactose synthetic medium lacking leucine $(a, c)$ and shifted to YPD for the times indicated $(b, d, e)$. Cells were fixed and stained with DAPI to visualize the nucleoplasm (shown in red). (B) Wild-type (a) and GAL::3HAnop53 strains $(b)$ containing pRpll1b-GFP (shown in green) were shifted to YPD for $4 \mathrm{~h}$. The nucleolus was visualized using an antiNoplp antibody (shown in red), and nucleoplasm was stained with DAPI (shown in blue).

competence, or to the export process itself. Studies in Xenopus oocytes (Trotta et al. 2003) have also linked $3^{\prime}$ maturation of the $5.8 \mathrm{~S}$ rRNA to $60 \mathrm{~S}$ subunit export, suggesting that this is a conserved feature.

While Nop53p is implicated in the nuclear export of pre$60 \mathrm{~S}$ subunits, a heterokaryon assay demonstrated that Nop53-GFP does not transfer between nuclei. This indicates that Nop53p does not accompany pre-60S particles into the cytoplasm. We hypothesize that Nop53p mediates an interaction between the pre-60S particles and the 
nuclear pore complex, consistent with the reported association of Nop53p with nucleoporins (Rout et al. 2000). Nop53p may dissociate prior to subunit translocation through the lumen of the pore, or be rapidly released and reimported following emergence of the preribosome on the cytoplasmic face of the NPC.

It seems likely that an important quality control system monitors subunit integrity prior to export to the cytoplasm. Only pre-60S subunits that are accurately assembled and sufficiently mature gain export competence. Export to the cytoplasm is presumably an irreversible step that takes the subunits beyond the reach of the nuclear RNA surveillance system, which appears to be more active than cytoplasmic surveillance. When the first mutants defective in subunit export were identified, it was assumed that the corresponding proteins functioned as components of the ribosomal subunit export machinery (Stage-Zimmermann et al. 2000). However, as the numbers of such "export factors" has grown, it has become increasingly unlikely that they all function directly in subunit export (Stage-Zimmermann et al. 2000; Baßler et al. 2001; Gadal et al. 2001a,b; Gleizes et al. 2001; Milkereit et al. 2001; Oeffinger et al. 2002, 2004; Fatica et al. 2003; Kallstrom et al. 2003; Milkereit et al. 2003; Galani et al. 2004). Rather, many mutations may inhibit export because they generate preribosomes that are perceived to be defective by a surveillance system that monitors the export-competence of the subunits.

NOP53 was initially reported to be essential for viability, based on a high-throughput screen. However, a very recent analysis found that a nop53 deletion strain is viable, although impaired in growth (Sydorskyy et al. 2005). The large majority of characterized yeast ribosome synthesis factors are essential for viability, and conditional mutants fail to synthesize one or more rRNA species under nonpermissive conditions. In most cases, they also accumulate only low levels of pre-rRNA, indicating that surveillance of preribosomes and degradation of pre-rRNAs are very active in yeast. This is in marked contrast to the situation in Escherichia coli, where ribosome synthesis is not known to be subject to surveillance activities. Mutations in ribosome synthesis factors are not lethal in E. coli, and generally lead to the accumulation of preribosomes and the synthesis of at least partially functional ribosomes (for review, see El Hage and Tollervey 2004). In this context, Nop53p is unusual among yeast ribosome synthesis and export factors, since its depletion resulted in a dramatic accumulation of the $7 \mathrm{~S}$ pre-rRNA. This indicates that the aberrant pre-60S ribosomes accumulated in this background are not subject to rapid degradation. Moreover, since Nop53p is nonessential, functional ribosomes must be synthesized in its absence. These observations would be consistent with the model that the lethality of many ribosome synthesis factors is a consequence of active surveillance.

The exosome complex of $3^{\prime}-5^{\prime}$ exonucleases is known to degrade aberrant pre-rRNAs that arise from the inhibition of processing (Allmang et al. 2000), and is a likely candidate to also degrade nuclear-restricted preribosomes. The exosome can be activated for RNA degradation in vitro and in vivo by the nuclear "TRAMP" complex (Trf4p, Air, Mtr4p polyadenylation complex) (LaCava et al. 2005; Vanacova et al. 2005; Wyers et al. 2005). This is comprised of a poly(A) polymerase Trf4p, a zinc-knuckle protein-either Air1p or Air2p, which are functionally redundant-and the putative RNA helicase Mtr4p. Strains lacking components of the TRAMP complex accumulate the aberrant $23 \mathrm{~S}$ pre-rRNA, which is a characterized substrate for the nuclear exosome (Allmang et al. 2000; LaCava et al. 2005). This indicates that the TRAMP complex functions together with the exosome in the surveillance and degradation of defective preribosomes. Nop53p was previously identified as protein that coprecipitated with FLAG-tagged Trf4p (Ho et al. 2002), suggesting the possibility that Nop53p also participates in the recognition of aberrant preribosomes. This would offer a potential explanation for the observation that preribosomes lacking Nop53p appear to be unusually resistant to RNA surveillance and degradation.

\section{MATERIALS AND METHODS}

\section{Strains and microbiological techniques}

Standard procedures were used for the propagation and maintenance of yeast. A full list of strains used in this study can be found in Table 1. YET1 and YET2 were constructed using a onestep PCR strategy (Longtine et al. 1998), during which transformants were selected for resistance to G418 and HIS prototrophy, respectively, and screened by PCR and immunoblotting. GAL conditional mutant and BMA38 wild type were transformed with pRpll1b-eGFP (kindly provided by P. Silver) to analyze the nuclear export of $60 \mathrm{~S}$ subunit, and a pAde vector for pulse chase analysis.

For depletion of GAL regulated Nop53p, cells were pregrown on permissive media containing $2 \%$ galactose harvested at various time intervals following a shift to nonpermissive media containing $2 \%$ glucose. Strains containing pRpll1b-eGFP were pregrown in galactose minimum media lacking leucine.

\section{Pulse chase analysis}

Metabolic labeling of pre-rRNA was performed as previously described (Tollervey et al. 1993) with the following modifications. The strains $B M A 38$ and GAL::3HA-nop53 were transformed with a plasmid containing $A D E 2$ gene. Strains were pregrown in synthetic galactose medium lacking adenine, and transferred to synthetic glucose medium lacking adenine for 1 h. Cells with an $\mathrm{OD}_{600} 0.4$ were labeled with $8-^{3} \mathrm{H}$ adenine for 2 or $5 \mathrm{~min}$, followed by a chase of excess cold adenine. Onemilliliter samples were spun down and cell pellets were frozen in liquid nitrogen. RNA was extracted and ethanol precipitated. 
TABLE 1. Yeast strains used and constructed in this study

\begin{tabular}{|c|c|c|}
\hline Strain & Genotype & Reference \\
\hline BMA38 & 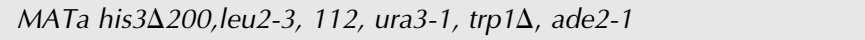 & Baudin et al. 1993 \\
\hline YET1 & As BMA38 but $K A N:: G A L 1:: 3 H A-y p / 146 c$ & This study \\
\hline BY4741 & MATa his $3 \Delta 1$, leu2so, met $15 \Delta 0$, ura $3 \Delta 0$ & Brachmann et al. 1998 \\
\hline Ypl146c-TAP & As BY4741 but yp/146c-TAP::HIS & Ghaemmaghami et al. 2003 \\
\hline YET2 & As BMA38 but yp/146c-eGFP::HIS & This study \\
\hline YET3 & As BMA38 but $p R p / 11 b-e G F P:: L E U$ & This study \\
\hline YET4 & As YET1 but $p R S 315 R p / 11 b-G F P:: L E U$ & This study \\
\hline YET5 & As BMA38 but $p$ Gar1-eGFP & This study \\
\hline MS740 & MAT $\alpha$ ade2-101, ura3-52, leu2-3, leu2-112, kar1-1 & Vallen et al. 1992 \\
\hline YMO17 & 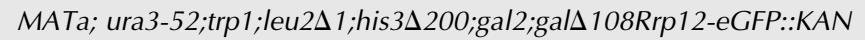 & Oeffinger et al. 2004 \\
\hline YET6 & As BMA38 but pAde & This study \\
\hline YET7 & As YET1 but $p A d e$ & This study \\
\hline
\end{tabular}

\section{RNA extraction, Northern hybridization, and primer extension}

RNA was extracted as previously described (Tollervey and Mattaj 1987). For high molecular weight RNA analysis $4 \mu \mathrm{g}$ of total RNA was glyoxyl denatured and resolved on a standard $1.2 \%$ agarose gel, as previously described (Sambrook and Russell 2001). Low molecular weight RNAs and primer extension products were resolved on standard 6\% Acrylamide/8.3 M urea gels. Primer extension reactions were carried out on $4 \mu \mathrm{g}$ of total RNA as previously described (Beltrame and Tollervey 1992).

Oligonucleotides for Northern hybridizations and primer extension:
003: 5'-TGCTTACCTCTGGGCC;
004: 5'-CGGTTTTAATTGTCCTA;
006: 5'-AGATTAGCCGCAGTTGG;
007: 5'-CTCCGCTTATTGATATGC;
008: 5'-CATGGCTTAATCTTTGAGAC
017: 5'-GCGTTGTTCATCGATGC;
020: 5'-TGAGAAGGAAATGACGCT;
041: 5'-CTACTCGGTCAGGCTC.

\section{Sucrose gradient analysis}

Sucrose gradient analysis was performed on a $10 \%$ to $50 \%$ gradient as previously described (Tollervey et al. 1993). RNA and protein was extracted from each fraction. RNA was resolved on standard 1.2\% Agarose-formaldehyde gels and 6\% acrylamide gels. Aliquots of each fraction were TCA precipitated and resolved using standard SDS-PAGE techniques. The sedimentation profile of Nop53-TAP was detected by immunoblotting with a peroxidaseconjugated rabbit IgG (Sigma).

\section{Fluorescence and immunofluorescence microscopy}

For immunofluorescence cells were fixed in 3.7\% paraformaldehyde at room temperature and spheroplasted using zymolase. Nop1p was detected with a mouse anti-Nop1 antibody (kindly provided by J. Aris, University of Florida), and a secondary goat antimouse antibody conjugated to Alexafluor 555 (Molecular Probes). To stain nuclear DNA, DAPI was included in the mounting medium (Vectashield, Vector laboratories) For Rpl11b-eGFP localization assays cells were pregrown in galactose synthetic media lacking leucine. Cells were shifted to YPD media and samples collected and fixed between 0 and $4 \mathrm{~h}$ at 30-min intervals.

\section{Heterokaryon assay}

Heterokaryon assays were carried out as previously described (Peng and Hopper 2000), with the following modifications. Mating was initiated by concentrating an equal number of Nop53-GFP cells and kar1-1 (provided by M. Rose, Princeton University) cells on a $25-\mathrm{mm}$ nitrocellulose filter with $0.45-\mu \mathrm{m}$ pore size, and incubated at $25^{\circ} \mathrm{C}$ on a YPD plate. Cells were removed from the membrane and fixed following $1-3 \mathrm{~h}$ of incubation, at 30-min intervals. Microscopy was carried out on a Leica DMR fluorescence microscope and pictures were captured using a Coolsnap CCD camera.

\section{ACKNOWLEDGMENTS}

We thank Mensur Dlakic (University of Montana) for his valued bioinformatic insights, and Christophe Dez for critical reading of the manuscript. E.T. was the recipient of a BBSRC studentship. This work was supported by the Wellcome Trust.

Received April 4, 2005; accepted May 2, 2005.

\section{REFERENCES}

Allmang, C., Kufel, J., Chanfreau, G., Mitchell, P., Petfalski, E., and Tollervey, D. 1999. Functions of the exosome in rRNA, snoRNA and snRNA synthesis. EMBO J. 18: 5399-5410.

Allmang, C., Mitchell, P., Petfalski, E., and Tollervey, D. 2000. Degradation of ribosomal RNA precursors by the exosome. Nucleic Acids Res. 28: 1684-1691.

Baßler, J., Grandi, P., Gadal, O., Leßmann, T., Petfalski, E., Tollervey, D., Lechner, J., and Hurt, E. 2001. Identification of a 60 S pre-ribosomal particle that is closely linked to nuclear export. Mol. Cell 8: 517-529.

Baudin, A., Ozier-Kalogeropoulos, O., Denouel, A., Lacroute, F., and Cullin, C. 1993. A simple and efficient method for direct gene deletion in Saccharomyces cerevisiae. Nucleic Acids Res. 21: 3329-3330. 
Beltrame, M. and Tollervey, D. 1992. Identification and functional analysis of two U3 binding sites on yeast pre-ribosomal RNA. EMBO J. 11: 1531-1542.

Brachmann, C.B., Davies, A., Cost, G.J., Caputo, E., Li, J., Hieter, P., and Boeke, J.D. 1998. Designer deletion strains derived from Saccharomyces cerevisiae S288C: A useful set of strains and plasmids for PCR-mediated gene disruption and other applications. Yeast 14: 115-132.

Briggs, M.W., Burkard, K.T., and Butler, J.S. 1998. Rrp6p, the yeast homologue of the human PM-Scl $100-\mathrm{kDa}$ autoantigen, is essential for efficient 5.8 S rRNA $3^{\prime}$ end formation. J. Biol. Chem. 273: 1325513263.

Dez, C., Froment, C., Noaillac-Depeyre, J., Monsarrat, B., CaizerguesFerrer, M., and Henry, Y. 2004. Npalp, a component of very early pre-60S ribosomal particles, associates with a subset of small nucleolar RNPs required for peptidyl transferase center modification. Mol. Cell. Biol. 24: 6324-6337.

Dragon, F., Gallagher, J.E., Compagnone-Post, P.A., Mitchell, B.M., Porwancher, K.A., Wehner, K.A., Wormsley, S., Settlage, R.E., Shabanowitz, J., Osheim, Y., et al. 2002. A large nucleolar U3 ribonucleoprotein required for $18 \mathrm{~S}$ ribosomal RNA biogenesis. Nature 417: 967-970.

El Hage, A., and Tollervey, D. 2004. A surfeit of factors: Why is ribosome assembly so much more complicated in Eukaryotes than Bacteria? RNA Biology 1: 10-15.

Fatica, A., Cronshaw, A.D., Dlakic, M., and Tollervey, D. 2002. Ssf1p prevents premature processing of an early pre-60S ribosomal particle. Mol. Cell 9: 341-351.

Fatica, A., Oeffinger, M., Tollervey, D., and Bozzoni, I. 2003. Ciclp/ $\mathrm{Nsa3p}$ is required for synthesis and nuclear export of $60 \mathrm{~S}$ ribosomal subunits. RNA 9: 1431-1436.

Gadal, O., Strauss, D., Braspenning, J., Hoepfner, D., Petfalski, E., Philippsen, P., Tollervey, D., and Hurt, E. 2001a. A nuclear AAAtype ATPase (Rix7p) is required for biogenesis and nuclear export of 60 S ribosomal subunits. EMBO J. 20: 3695-3704.

Gadal, O., Strauss, D., Kessl, J., Trumpower, B., Tollervey, D., and Hurt, E. 2001b. Nuclear export of 60s ribosomal subunits depends on Xpolp and requires a nuclear export sequence-containing factor, Nmd3p, that associates with the large subunit protein Rpl10p. Mol. Cell. Biol. 21: 3405-3415.

Gadal, O., Strauss, D., Petfalski, E., Gleizes, P.E., Gas, N., Tollervey, D., and Hurt, E. 2002. Rlp7p is associated with 60 S preribosomes, restricted to the granular component of the nucleolus, and required for pre-rRNA processing. J. Cell Biol. 157: 941-951.

Galani, K., Nissan, T.A., Petfalski, E., Tollervey, D., and Hurt, E. 2004. Real, a dynein-related nuclear AAA-ATPase, is involved in late rRNA processing and nuclear export of $60 \mathrm{~S}$ subunits. J. Biol. Chem. 279: 55411-55418.

Ghaemmaghami, S., Huh, W.K., Bower, K., Howson, R.W., Belle, A., Dephoure, N., O'Shea, E.K., and Weissman, J.S. 2003. Global analysis of protein expression in yeast. Nature 425: 737-741.

Gleizes, P.E., Noaillac-Depeyre, J., Leger-Silvestre, I., Teulieres, F., Dauxois, J.Y., Pommet, D., Azum-Gelade, M.C., and Gas, N. 2001. Ultrastructural localization of rRNA shows defective nuclear export of preribosomes in mutants of the Nup82p complex. J. Cell Biol. 155: 923-936.

Grandi, P., Rybin, V., Bassler, J., Petfalski, E., Strauss, D., Marzioch, M., Schafer, T., Kuster, B., Tschochner, H., Tollervey, D., et al. 2002. $90 \mathrm{~S}$ pre-ribosomes include the $35 \mathrm{~S}$ pre-rRNA, the U3 snoRNP, and $40 \mathrm{~S}$ subunit processing factors but predominantly lack $60 \mathrm{~S}$ synthesis factors. Mol. Cell 10: 105-115.

Harnpicharnchai, P., Jakovljevic, J., Horsey, E., Miles, T., Roman, J., Rout, M., Meagher, D., Imai, B., Guo, Y., Brame, C.J., et al. 2001. Composition and functional characterization of yeast $66 \mathrm{~s}$ ribosome assembly intermediates. Mol. Cell 8: 505-515.

Ho, Y., Gruhler, A., Heilbut, A., Bader, G.D., Moore, L., Adams, S.L., Millar, A., Taylor, P., Bennett, K., Boutilier, K., et al. 2002. Systematic identification of protein complexes in Saccharomyces cerevisiae by mass spectrometry. Nature 415: 180-183.
Horsey, E.W., Jakovljevic, J., Miles, T.D., Harnpicharnchai, P., and Woolford Jr., J.L. 2004. Role of the yeast Rrp1 protein in the dynamics of pre-ribosome maturation. RNA 10: 813-827.

Kallstrom, G., Hedges, J., and Johnson, A. 2003. The putative GTPases Nog1p and Lsg1p are required for 60S ribosomal subunit biogenesis and are localized to the nucleus and cytoplasm, respectively. Mol. Cell Biol. 23: 4344-4355.

LaCava, J., Houseley, J., Saveanu, C., Petfalski, E., Thompson, E., Jacquier, A., and Tollervey, D. 2005. RNA degradation by the exosome is promoted by a nuclear polyadenylation complex. Cell 121: 713-724.

Longtine, M.S., McKenzie 3rd, A., Demarini, D.J., Shah, N.G., Wach, A., Brachat, A., Philippsen, P., and Pringle, J.R. 1998. Additional modules for versatile and economical PCR-based gene deletion and modification in Saccharomyces cerevisiae. Yeast 14: 953-961.

Milkereit, P., Gadal, O., Podtelejnikov, A., Trumtel, S., Gas, N., Petfalski, E., Tollervey, D., Mann, M., Hurt, E., and Tschochner, H. 2001. Maturation and intranuclear transport of pre-ribosomes requires Noc proteins. Cell 105: 499-509.

Milkereit, P., Strauss, D., Bassler, J., Gadal, O., Kuhn, H., Schutz, S., Gas, N., Lechner, J., Hurt, E., and Tschochner, H. 2003. A Noc complex specifically involved in the formation and nuclear export of ribosomal $40 \mathrm{~S}$ subunits. J. Biol. Chem. 278: 4072-4081.

Nissan, T.A., Baßler, J., Petfalski, E., Tollervey, D., and Hurt, E. 2002. $60 \mathrm{~S}$ pre-ribosome formation viewed from assembly in the nucleolus until export to the cytoplasm. EMBO J. 21: 5539-5547.

Oeffinger, M., Leung, A., Lamond, A., and Tollervey. D. 2002. Yeast Pescadillo is required for multiple activities during 60S ribosomal subunit synthesis. RNA 8: 626-636.

Oeffinger, M., Dlakic, M., and Tollervey, D. 2004. A pre-ribosomeassociated HEAT-repeat protein is required for export of both ribosomal subunits. Genes \& Dev. 18: 196-209.

Peng, G. and Hopper, J.E. 2000. Evidence for Gal3p's cytoplasmic location and Gal80p's dual cytoplasmic-nuclear location implicates new mechanisms for controlling Gal4p activity in Saccharomyces cerevisiae. Mol. Cell. Biol. 20: 5140-5148.

Rigaut, G., Shevchenko, A., Rutz, B., Wilm, M., Mann, M., and Seraphin, B. 1999. A generic protein purification method for protein complex characterization and proteome exploration. Nat. Biotechnol. 17: 1030-1032.

Rout, M.P., Aitchison, J.D., Suprapto, A., Hjertaas, K., Zhao, Y., and Chait, B.T. 2000. The yeast nuclear pore complex: Composition, architecture, and transport mechanism. J. Cell Biol. 148: 635-651.

Sambrook, J. and Russell, D.W. 2001. Molecular cloning. Cold Spring Harbor Laboratory Press, Cold Spring Harbor, NY.

Saveanu, C., Bienvenu, D., Namane, A., Gleizes, P.-E., Gas, N., Jacquier, A., and Fromont-Racine, M. 2001. Nog2p, a putative GTPase associated with pre-60S subunits and required for late 60S maturation steps. EMBO J. 20: 6475-6484.

Saveanu, C., Namane, A., Gleizes, P.-E., Lebreton, A., Rousselle, J.-C., Noaillac-Depeyre, J., Gas, N., Jacquier, A., and Fromont-Racine, M. 2003. Sequential protein association with nascent $60 \mathrm{~S}$ ribosomal particles. Mol. Cell. Biol. 23: 4449-4460.

Schafer, T., Strauss, D., Petfalski, E., Tollervey, D., and Hurt, E. 2003. The path from nucleolar $90 \mathrm{~S}$ to cytoplasmic $40 \mathrm{~S}$ pre-ribosomes. EMBO J. 22: 1370-1380.

Smith, J.S., Tachibana, I., Lee, H.K., Qian, J., Pohl, U., Mohrenweiser, H.W., Borell, T.J., Hosek, S.M., Soderberg, C.L., von Deimling, A., et al. 2000. Mapping of the chromosome 19 q-arm glioma tumor suppressor gene using fluorescence in situ hybridization and novel microsatellite markers. Genes Chromosomes Cancer 29: 16-25.

Stage-Zimmermann, T., Schmidt, U., and Silver, P.A. 2000. Factors affecting nuclear export of the $60 \mathrm{~S}$ ribosomal subunit in vivo. Mol. Biol. Cell 11: 3777-3789.

Sydorskyy, Y., Dilworth, D.J., Halloran, B.P., Yi, E.C., Makhnevych, T.R., Wozniak, R.W., and Aitchison, J.D. 2005. Nop53p is a novel nucleolar 60S ribosomal biogenesis protein. Biochem J. 388 (Part 3): 819-826.

Tollervey, D. and Mattaj, I.W. 1987. Fungal small nuclear ribonucleoproteins share properties with plant and vertebrate U-snRNPs. EMBO J. 6: 469-476. 
Tollervey, D., Lehtonen, H., Jansen, R., Kern, H., and Hurt, E.C. 1993. Temperature-sensitive mutations demonstrate roles for yeast fibrillarin in pre-rRNA processing, pre-rRNA methylation, and ribosome assembly. Cell 72: 443-457.

Trotta, C.R., Lund, E., Kahan, L., Johnson, A.W., and Dahlberg, J.E. 2003. Coordinated nuclear export of 605 ribosomal subunits and NMD3 in vertebrates. EMBO J. 22: 2841-2851.

Tschochner, H. and Hurt, E. 2003. Pre-ribosomes on the road from the nucleolus to the cytoplasm. Trends Cell Biol. 13: 255-263.

Vallen, E.A., Hiller, M.A., Scherson, T.Y., and Rose, M.D. 1992. Separate domains of KAR1 mediate distinct functions in mitosis and nuclear fusion. J. Cell Biol. 117: 1277-1287.

Vanacova, S., Wolf, J., Martin, G., Blank, D., Dettwiler, S., Friedlein, A., Langen, H., Keith, G., and Keller, W. 2005. A new yeast poly(A) polymerase complex involved in RNA quality control. PLoS Biol. 3: e189.
Venema, J. and Tollervey, D. 1999. Ribosome synthesis in Saccharomyces cerevisiae. Ann. Rev. Gen. 33: 261-311.

Winzeler, E.A., Shoemaker, D.D., Astromoff, A., Liang, H., Anderson, K., Andre, B., Bangham, R., Benito, R., Boeke, J.D., Bussey, H., et al. 1999. Functional characterization of the $S$. cerevisiae genome by gene deletion and parallel analysis. Science 285: 901-906.

Wu, P., Brockenbrough, J.S., Metcalfe, A.C., Chen, S., and Aris, J.P. 1998. Nop5p is a small nucleolar ribonucleoprotein component required for pre-18 S rRNA processing in yeast. J. Biol. Chem. 273: 16453-16463.

Wyers, F., Rougemaille, M., Badis, G., Rousselle, J.-C., Dufour, M.-.E., Boulay, J., Régnault, B., Devaux, F., Namane, A., Séraphin, B., et al. 2005. Cryptic Pol II transcripts are degraded by a nuclear quality control pathway involving a new poly(A) polymerase. Cell 121: 725-737. 

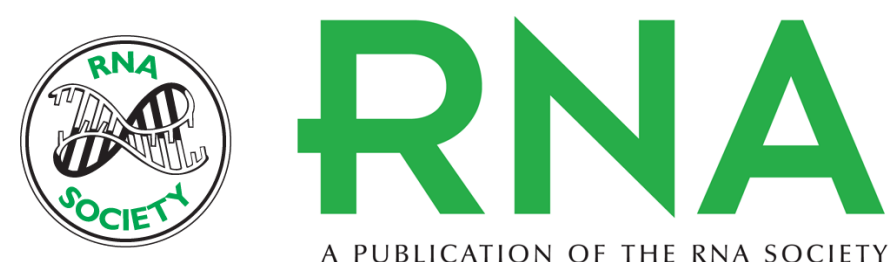

A PUBLICATION OF THE RNA SOCIETY

\section{Nop53p is required for late $60 \mathrm{~S}$ ribosome subunit maturation and nuclear export in yeast}

EMMA THOMSON and DAVID TOLLERVEY

RNA 2005 11: 1215-1224

References This article cites 49 articles, 24 of which can be accessed free at: http://rnajournal.cshlp.org/content/11/8/1215.full.html\#ref-list-1

\section{License}

Email Alerting Receive free email alerts when new articles cite this article - sign up in the box at the Service top right corner of the article or click here. 